\title{
Establishment of a duplex real-time qPCR method for detection of Salmonella spp. and Serratia fonticola in fishmeal
}

\author{
Jinghua Ruan ${ }^{2,4 \dagger}$, Wujun Wang ${ }^{1,2,3 \dagger}$, Tiyin Zhang ${ }^{3}$, Teng Zheng ${ }^{3}$, Jing Zheng ${ }^{3}$, Shiyu Yu ${ }^{3}$, Daojin Y 2 $^{*}$ \\ and Yifan Huang $2^{2^{*}}$
}

\begin{abstract}
Salmonella spp. is a high-risk bacterial pathogen that is monitored in imported animal-derived feedstuffs. Serratia fonticola is the bacterial species most frequently confused with Salmonella spp. in traditional identification methods based on biochemical characteristics, which are time-consuming and labor-intensive, and thus unsuitable for daily inspection and quarantine work. In this study, we established a duplex real-time qPCR method with invA- and gyrBspecific primers and probes corresponding to Salmonella spp. and S. fonticola. The method could simultaneously detect both pathogens in imported feedstuffs, with a minimum limit of detection for Salmonella spp. and S. fonticola of 197 copies/ $\mu \mathrm{L}$ and 145 copies/ $\mu \mathrm{L}$, respectively (correlation coefficient $R^{2}=0.999$ in both cases). The amplification efficiency for Salmonella spp. and S. fonticola was $98.346 \%$ and $96.49 \%$, respectively. Detection of fishmeal was consistent with method GB/T 13091-2018, and all seven artificially contaminated imported feed samples were positively identified. Thus, the developed duplex real-time qPCR assay displays high specificity and sensitivity, and can be used for the rapid and accurate detection of genomic DNA from Salmonella spp. and S. fonticola within hours. This represents a significant improvement in the efficiency of detection of both pathogens in imported feedstuffs.
\end{abstract}

Keywords: Salmonella spp., S. fonticola, Duplex real-time qPCR, Feed safety

\section{Introduction}

Salmonella spp. are ubiquitous Gram-negative bacteria in the environment and include six different subspecies and more than 2000 serotypes that infect a wide range of hosts, often causing severe food poisoning outbreaks in humans and other animals. People infected with Salmonella can develop diarrhea, fever, and suffer dehydration, hence Salmonella spp. are of significance to public health.

S. fonticola is a species belonging to the Serratia genus that was first isolated from water and soil in 1979 (Gavini et al. 1979). Subsequent studies showed that S. fonticola,

\footnotetext{
*Correspondence: yudaojin@yeah.net; zjhyfang@163.com

†Jinghua Ruan and Wujun Wang have contributed equally to this work

${ }^{2}$ Fujian Key Laboratory of Traditional Chinese Veterinary Medicine

and Animal Health, Fujian Agriculture and Forestry University,

Fuzhou 350002, Fujian, People's Republic of China

Full list of author information is available at the end of the article
}

a member the Gram-negative Enterobacteriaceae family that includes Salmonella spp., is also ubiquitous in environments such as water, soil, plants, and the gastrointestinal tract of humans and other animals (Tasic et al. 2013). Research has revealed that $S$. fonticola can infect various tissues and organs in humans, causing septic arthritis, septicemia, gastrointestinal tract infections, and surgical infections (Rd et al. 1985; Bollet et al. 1991; Kunimoto et al. 2004). Therefore S. fonticola have been defined as an important opportunistic pathogen.

At present, the detection of Salmonella spp. in imported animal-derived feeds (fish meal and chicken powder) involves non-selective enrichment, selective enrichment, selective platelet culturing, biochemical culturing of suspected Salmonella colonies (triglyceride tests, etc.), and even serological typing. These conventional methods require at least 3 days to detect
Springer Open (c) The Author(s) 2020. This article is licensed under a Creative Commons Attribution 4.0 International License, which permits use, sharing, adaptation, distribution and reproduction in any medium or format, as long as you give appropriate credit to the original author(s) and the source, provide a link to the Creative Commons licence, and indicate if changes were made. The images or other third party material in this article are included in the article's Creative Commons licence, unless indicated otherwise in a credit line to the material. If material is not included in the article's Creative Commons licence and your intended use is not permitted by statutory regulation or exceeds the permitted use, you will need to obtain permission directly from the copyright holder. To view a copy of this licence, visit http://creativeco mmons.org/licenses/by/4.0/. 
Salmonella spp. in daily quarantine work. Furthermore, suspected Salmonella colonies based on selective plate isolation and culturing of imported animal-derived feeds often turn out to be $S$. fonticola when biochemical properties are investigated (Chen et al. 2016). The enzyme linked immune sorbent assay (ELISA) method is commonly used for detecting pathogens in imported animal-derived feeds, but this method can produce incorrect results due to its cumbersome operational steps. A novel method involving polymer fluorescent nanoparticles as biosensor probes has been described for the detection of Salmonella (Jain et al. 2016), which takes only $3 \mathrm{~h}$, but cannot be applied to large volume detection due to its prohibitively high cost.

Traditional PCR and multiplex PCR methods have been developed for the detection of Salmonella species and Serratia genus attributed to its high sensitivity, specificity, and results can be obtained within several hours. Multi-PCR approaches can differentiate two or more pathogens in one amplification, however, products are easily contaminated during agarose gel electrophoresis, which increases false-positive and false-negative results. Thus, a more reliable approach such as real-time fluorescence quantitative PCR (RTqPCR) would be more desirable for the rapid and accurate detection of pathogens. RT-qPCR methods are known to be fast, reliable, and highly efficient. Several single RT-qPCR methods for detecting $S$. nematodiphila (Hurst et al. 2008), S. marcescens (Iwaya et al. 2005; Joyner et al. 2014; Cornegliani et al. 2015) and Salmonella spp. (Perelle et al. 2004; Nam et al. 2005; Tomás et al. 2009) have been described.

Previous studies on fish meal and other animal-derived feeds have mainly focused on the detection and epidemiology of Salmonella, Shigella, Escherichia coli, and other common pathogenic bacteria. A method for the simultaneous detection of Salmonella spp. and S. fonticola in imported animal-derived feeds using RT-qPCR has not been reported. Such a method could provide rapid differential diagnosis of suspected Salmonella colonies after selective plate separation and culturing. This would undoubtedly improve the detection of Salmonella, and greatly shorten the time required for subsequent biochemical and serological identification, saving valuable manpower and material resources.

The duplex real-time qPCR method established in the present work provides a useful tool for the simultaneous detection of Salmonella spp. and S. fonticola. The method has important theoretical significance and great potential for improving the safety of imported feeds by rapidly identifying bacterial pathogens and facilitating effective quarantining in a more timely manner than traditional detection methods.

\section{Materials and methods Bacterial strains}

A total of 48 tested strains were used in this study, including 17 reference strains from six different collection centers, and 31 isolates from imported fishmeal (Additional file 1: Tables S1-S3). All experimental strains were streaked on nutrient agar plates and cultured in LuriaBertani (LB) broth at $37^{\circ} \mathrm{C}$ overnight $(\sim 18-24 \mathrm{~h})$, except for $S$. marcescens, which was grown at $23^{\circ} \mathrm{C}$ for $24 \mathrm{~h}$. An established single colony was inoculated into $3 \mathrm{~mL}$ of $\mathrm{LB}$ broth for $8 \mathrm{~h}$ and the resultant culture was harvested for genomic DNA extraction.

\section{Sample collection and bacterial isolation}

A $25 \mathrm{~g}$ sample of fishmeal was added to $225 \mathrm{~mL}$ of buffered peptone water (BPW) and incubated at $36 \pm 1{ }^{\circ} \mathrm{C}$ for between $16-20 \mathrm{~h}$. A $10 \mathrm{~mL}$ sample of this pre-enrichment culture was transferred into $100 \mathrm{~mL}$ of enrichment solution containing selenite cysteine (SC enrichment solution), cultured at $36 \pm 1{ }^{\circ} \mathrm{C}$ for $24 \mathrm{~h}$, and inoculated onto CHROMagar ${ }^{\mathrm{TM}}$ Salmonellae (CHROMagar) designed for Salmonella spp. Two Salmonella spp. colonies were cultured at $36 \pm 1{ }^{\circ} \mathrm{C}$ for $48 \mathrm{~h}$ in CHROMagar, one on the medium slope, the other punctured through the agar, and both were then inoculated on trisaccharide iron medium. Meanwhile, suspicious colonies were inoculated onto lysine decarboxylase medium and cultured at $36 \pm 1{ }^{\circ} \mathrm{C}$ for $18-24 \mathrm{~h}$ (or up to $48 \mathrm{~h}$ if necessary). Colonies from positive samples presumed to be Salmonella spp. were further identified using a VITEK II Compact 30 instrument (BioMérieux) with a GN card according to the manufacturer's specifications. DNA extraction from isolates and reference strains was performed with a TIANamp Bacteria DNA Kit (Tiangen Biotech, Co., Ltd, Beijing, China) according to the manufacturer's recommendations.

\section{Species-specific primers and probes design}

The invA sequences of Salmonella spp. were aligned to identify conserved and specific regions using CLUSTAL W software (Aiyar 2000). A series of sense and antisense primers were designed based on these conserved and specific regions using ABI ViiA7 PrimerExpress software, and the final specific primer pair and dual-labelled probe (Additional file 1: Table S4) targeting the Salmonella spp. virulence gene were determined using the basic logical alignment search tool (BLAST) (Altschul et al. 1997). Primers and dual-labelled probe targeting the $\operatorname{gyr} B$ gene were as described our previous research (Ruan et al. 2017). The primers and probes sets were synthesized by Sangon Biotech (Shanghai, China), and probes labeled with the fluorescent reporter dye carboxy-4' $4^{\prime} 5^{\prime}$-dichloro$2^{\prime}, 7^{\prime}$-dimethoxyfluorescein (JOE) targeting $\operatorname{inv} A$ and 
6-carboxyfluorescein (FAM) targeting gyrB were covalently coupled to the $5^{\prime}$-end, with Black Hole Quencher 1 (BHQ-1) at the $3^{\prime}$-end.

\section{Single real-time $\mathrm{qPCR}$ assays}

The optimum annealing temperature of primers were screened using a Bio-rad CFX96 Real-time PCR system (Bio-Rad Laboratories, Inc., USA). Two simplex RTqPCR detection methods for the detection of Salmonella spp. and S. fonticola were established using primers and probes targeting inv $A$ and gyr $B$ genes, respectively, using an Applied Biosystems ViiA 7 real-time PCR system (Life Technologies Inc., Foster City, CA, USA). Reaction conditions were determined after various PCR parameters were tested according to the information supplied with the reagents. The optimized $20 \mu \mathrm{L}$ PCR contained $10 \mu \mathrm{L}$ of $2 \times$ Premix Ex Taq (TaKaRa Biomedical Technology Co., Ltd), $0.4 \mu \mathrm{L}$ of each primer $(10 \mu \mathrm{M})$ and probe $(10 \mu \mathrm{M}), 0.2 \mu \mathrm{L}$ of ROX Reference Dye $(50 \times), 1$ $\mu \mathrm{L}$ of bacterial DNA, and $7.6 \mu \mathrm{L}$ of Rnase-free $\mathrm{ddH}_{2} \mathrm{O}$. Optimized thermal cycling conditions involved an initial denaturation at $95{ }^{\circ} \mathrm{C}$ for $30 \mathrm{~s}$, followed by 40 cycles at $95{ }^{\circ} \mathrm{C}$ for $5 \mathrm{~s}$ and $64{ }^{\circ} \mathrm{C}$ for $34 \mathrm{~s}$. ViiA 7 Software was employed to monitor PCR amplification, and the collect and analyze amplification data.

To verify the specificity of the two simplex RT-qPCR assays, tests were performed by amplifying genomic DNA extracted from strains. We constructed recombinant plasmids carrying invA and $\operatorname{gyr} B$ gene to determine the sensitivity of two simplex real-time qPCR. The standard plasmids of pMD-invA and pMD-gyr $B$ were serially diluted 9 times with ten-fold and then subjected to RTqPCR to make standard curves(three technical replications for each dilution), from which we determined both the amplification efficiency and the minimum detection limit of the two real-time qPCR methods. The plasmid copy numbers was calculated using the following formula (Whelan et al. 2003):

$$
\begin{aligned}
\text { Copy number }= & (\text { DNA amount }(\mathrm{ng}) \times 6.022 \\
& \left.\times 10^{23} / \text { length }(\mathrm{bp}) \times 10^{9} \times 650\right) .
\end{aligned}
$$

\section{Duplex real-time qPCR assay}

A duplex real-time qPCR assay was established based on the two simplex RT-qPCR assays developed for the detection of Salmonella spp. and S. fonticola using an equal amount of genomic DNA from the two pathogens in the same reaction. Optimal PCR conditions were ultimately determined based on the simplex RT-qPCR parameters described above by varying a single factor while all other parameters remained constant. The main factor to be investigated was the concentration of the two primer and probe sets since the annealing temperatures of primers and probes was already optimized.

To analyze the reproducibility and stability of the established duplex real-time qPCR method, recombinant $\mathrm{pMD}-i n v A$ and $\mathrm{pMD}-$ gyr $B$ plasmids were tenfold serially diluted five times (each dilution was tested in triplicate). A total of 96 reactions were simultaneously performed using the $i n v A$ - and $\operatorname{gyr} B$ recombinant plasmids in the same real-time qPCR mixture to verify reproducibility. The coefficient of variation (CV) based on quantification cycle $(\mathrm{Cq})$ values for each test was used to evaluate the performance of this approach.

\section{Detection of artificially contaminated feed stuffs}

A $10 \mathrm{~mL}$ sample of this pre-enrichment culture was transferred into $100 \mathrm{~mL}$ of SC enrichment solution, cultured at $36 \pm 1{ }^{\circ} \mathrm{C}$ for $24 \mathrm{~h}$, and inoculated onto CHROMagar designed for Salmonella spp. Two Salmonella spp. colonies were cultured at $36 \pm 1{ }^{\circ} \mathrm{C}$ for $48 \mathrm{~h}$ in CHROMagar, one on the medium slope, the other punctured through the agar, and both were then inoculated on trisaccharide iron medium. Meanwhile, suspicious colonies were inoculated onto lysine decarboxylase medium and cultured at $36 \pm 1{ }^{\circ} \mathrm{C}$ for $18-24 \mathrm{~h}$ (or up to $48 \mathrm{~h}$ if necessary).

We tested seven imported fishmeal samples not contaminated by either Salmonella spp. or S. fonticola. A $25 \mathrm{~g}$ portion of three of the fishmeal samples was artificially contaminated with Salmonella enteritidis and S. fonticola $\left(2 \times 10^{6} \mathrm{CFU} / \mathrm{g}\right)$, while the other four samples were contaminated with Salmonella enteritidis $\left(2 \times 10^{6} \mathrm{CFU} / \mathrm{g}\right)$. Contaminated samples were added to $225 \mathrm{~mL}$ of BPW enrichment solution and incubated at $36 \pm 1{ }^{\circ} \mathrm{C}$ for $16-20 \mathrm{~h}$. A $1 \mathrm{~mL}$ sample of the pre-enrichment culture was transferred into $10 \mathrm{~mL}$ of SC enrichment solution, cultured at $36 \pm 1{ }^{\circ} \mathrm{C}$ for $24 \mathrm{~h}$. Then $1 \mathrm{~mL}$ of above solution was used for genomic DNA extraction using the TIANamp Bacteria DNA Kit (Tiangen Biotech, Co., Ltd). Finally, RT-qPCR was performed for the detection of Salmonella spp. and S. fonticola, and the national standard method (GB/T13091-2018) was also employed for verification.

\section{Results}

\section{Determination of optimum annealing temperature}

Genomic DNA from Salmonella enteritidis and $S$. fonticola was used as a template to determine optimal annealing temperatures for the two primer sets by testing between 55 and $65{ }^{\circ} \mathrm{C}$ using a Bio-Rad fluorescence quantitative PCR instrument. RT-qPCR using the designed primers and probes yielded the 
highest fluorescence intensity of amplified products at an annealing temperature of $64.5^{\circ} \mathrm{C}$ for both invA- and gyrB- specific primers and probes, and this annealing temperature was employed in subsequent experiments.

\section{Specificity of the single real-time qPCR assay}

The specificity of the two single real-time qPCR assays was verified by amplifying genomic DNA extracted from reference strains and laboratory isolates. The real-time qPCR assay detected Salmonella spp. only, while no fluorescent signal was observed for any nonSalmonella spp. strains or blank controls. Additionally, the real-time qPCR assay targeting $S$. fonticola generated four specific amplification curves for the detection of four S. fonticola strains, while non-S. fonticola and blank controls were not amplified. Thus, the specificity of the two real-time qPCR assays was $100 \%$, with no detectable fluorescent signal for negative samples or blank controls.

\section{Standard curves and sensitivity of the simplex real-time qPCR assay}

Recombinant invA- and gyrB-containing plasmids were tenfold serially diluted nine times, resulting in real-time qPCR amplicon copy numbers from $1.97 \times 10^{10}$ copies/ $\mu \mathrm{L}$ to $1.97 \times 10^{2}$ copies $/ \mu \mathrm{L}$, and $1.45 \times 10^{10}$ copies $/ \mu \mathrm{L}$ to $1.45 \times 10^{2}$ copies $/ \mu \mathrm{L}$, respectively. The standard curve for invA has a $\gamma$ intercept of 48.116 , a slope of -3.267 , and a mean efficiency of $102.344 \%$ (Fig. 1a). The gyrB standard curve has a $\gamma$ intercept of 42.919, a slope of -3.242 , and a mean efficiency of $103.429 \%$ (Fig. 1b). As shown in Fig. 1c, d, the single quantitative real-time PCR assays could detect Salmonella spp. and S. fonticola at concentrations as low as 197 and 145 copies per reaction, respectively.

\section{Establishment of the duplex real-time qPCR}

Figure 2a, b shows amplification plots and standard curves for the duplex real-time qPCR assay established for simultaneous detection of Salmonella spp. and S. fonticola developed with recombinant $\mathrm{pUCm}$-invA and $\mathrm{pUCm}-\mathrm{gyr} B$

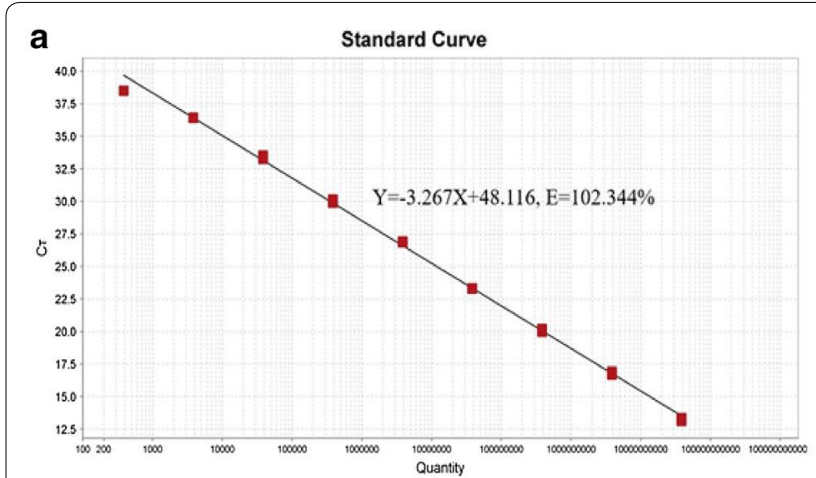

b
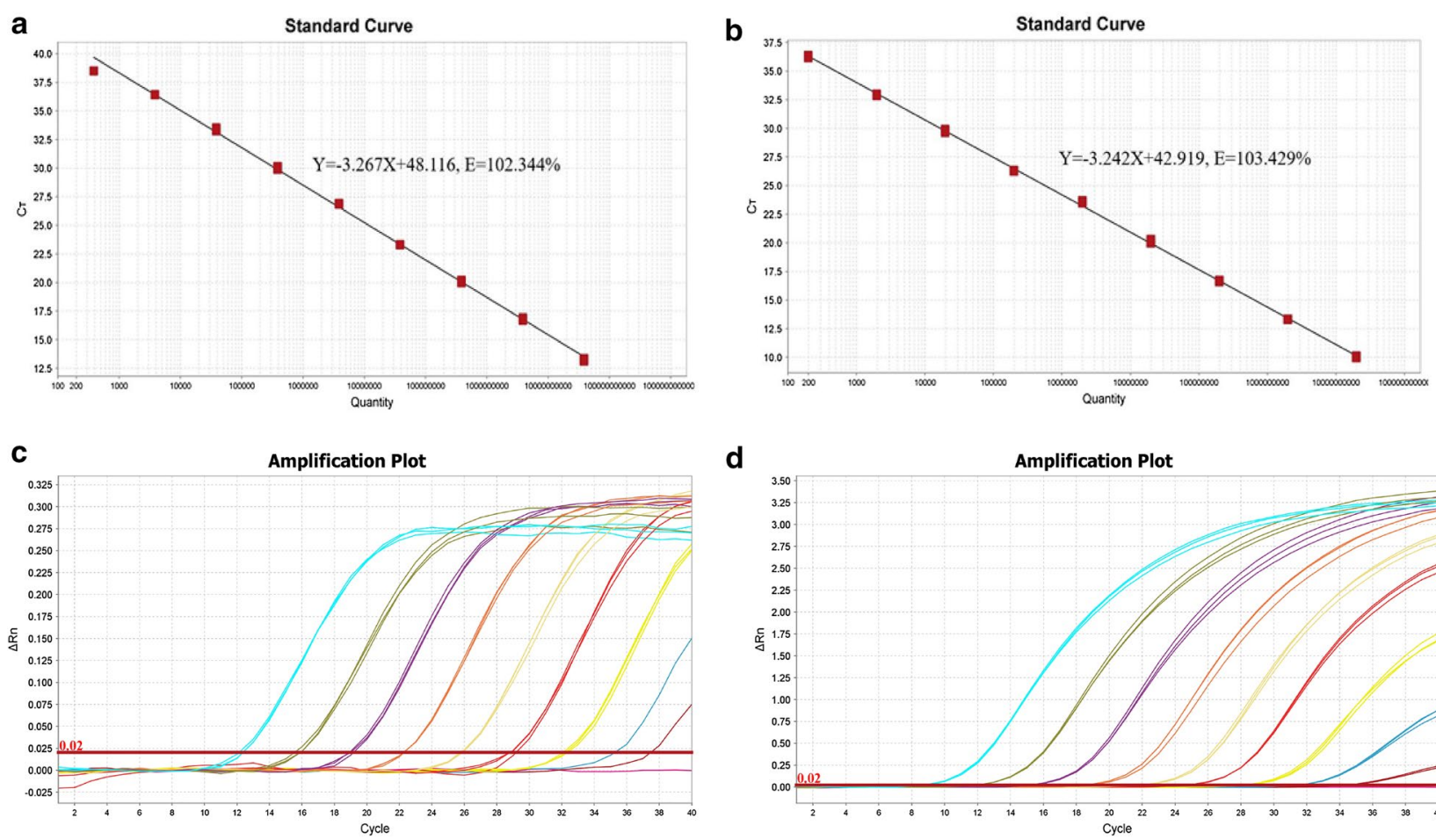

d

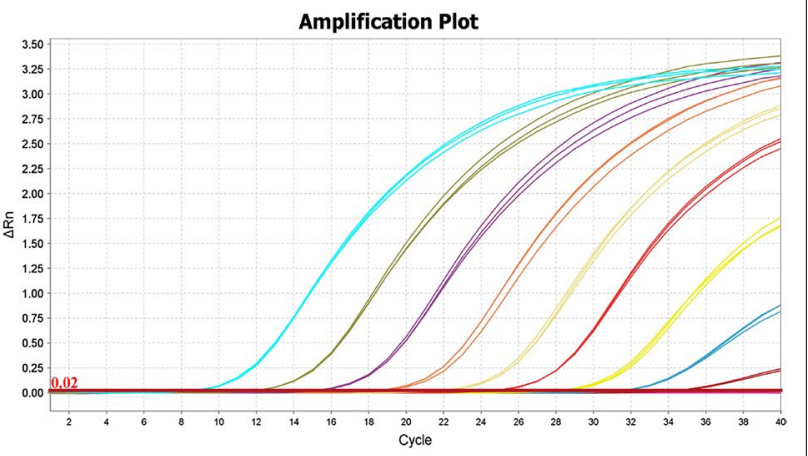

Fig. 1 Standard curves and sensitivity of the real-time qPCR assay. Standard curves for Salmonella. app (a) and S. fonticola (b) RT-qPCR assay. The curves represent a range from $10^{10}$ to $10^{2}$ copies per reaction. Sensitivity of the real-time qPCR assay for the detection of Salmonella species (c) and S. fonticola (d). Amplification plots from left to right represent a range of invA/gyrB gene-containing plasmids from $1.97 \times 10^{10}$ to $1.97 \times 10^{2} \mathrm{copies} /$ $\mu \mathrm{L}\left(1.45 \times 10^{10}\right.$ to $1.45 \times 10^{2}$ copies $\left./ \mu \mathrm{L}\right)$, respectively 


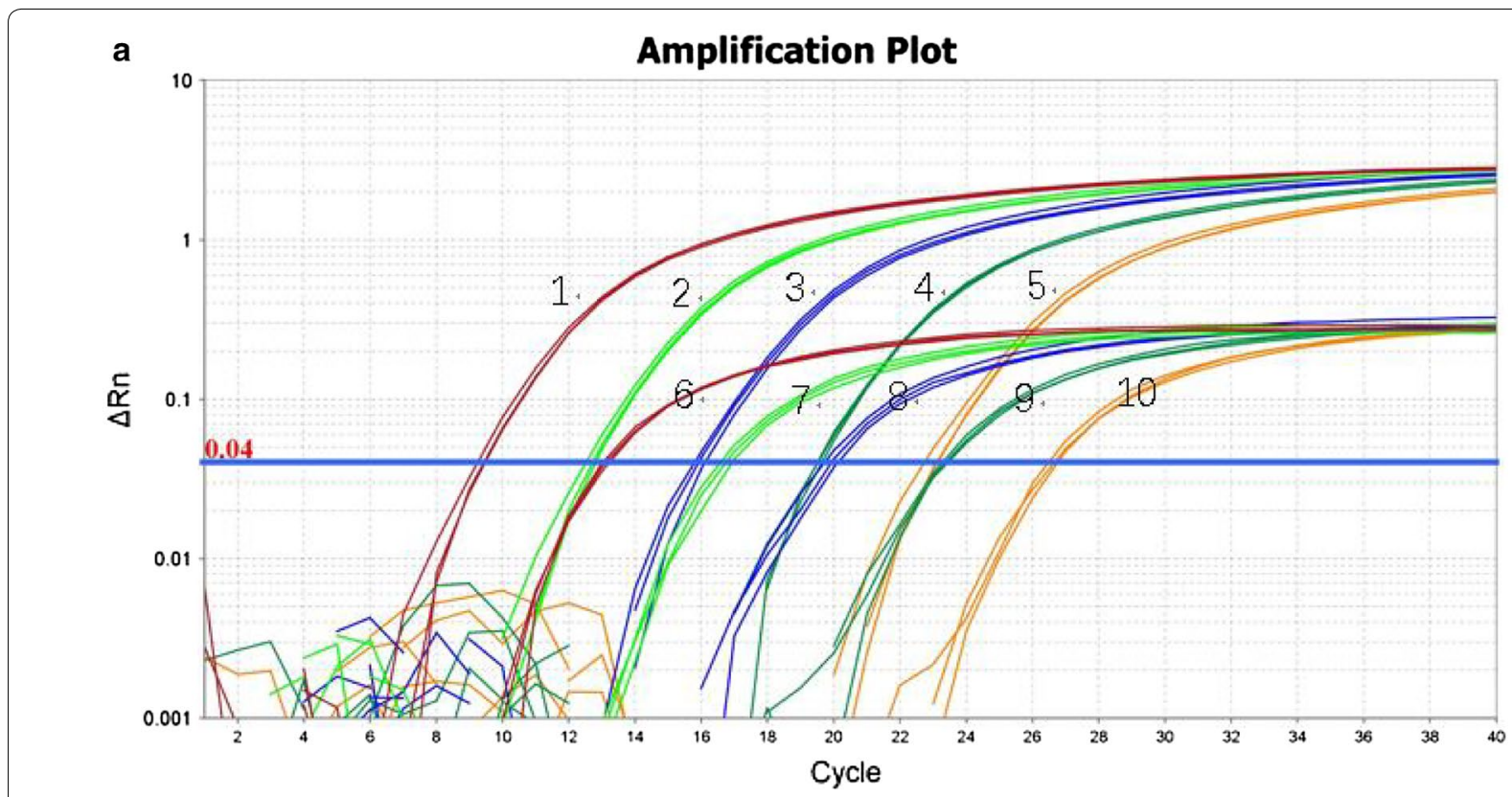

b

Standard Curve

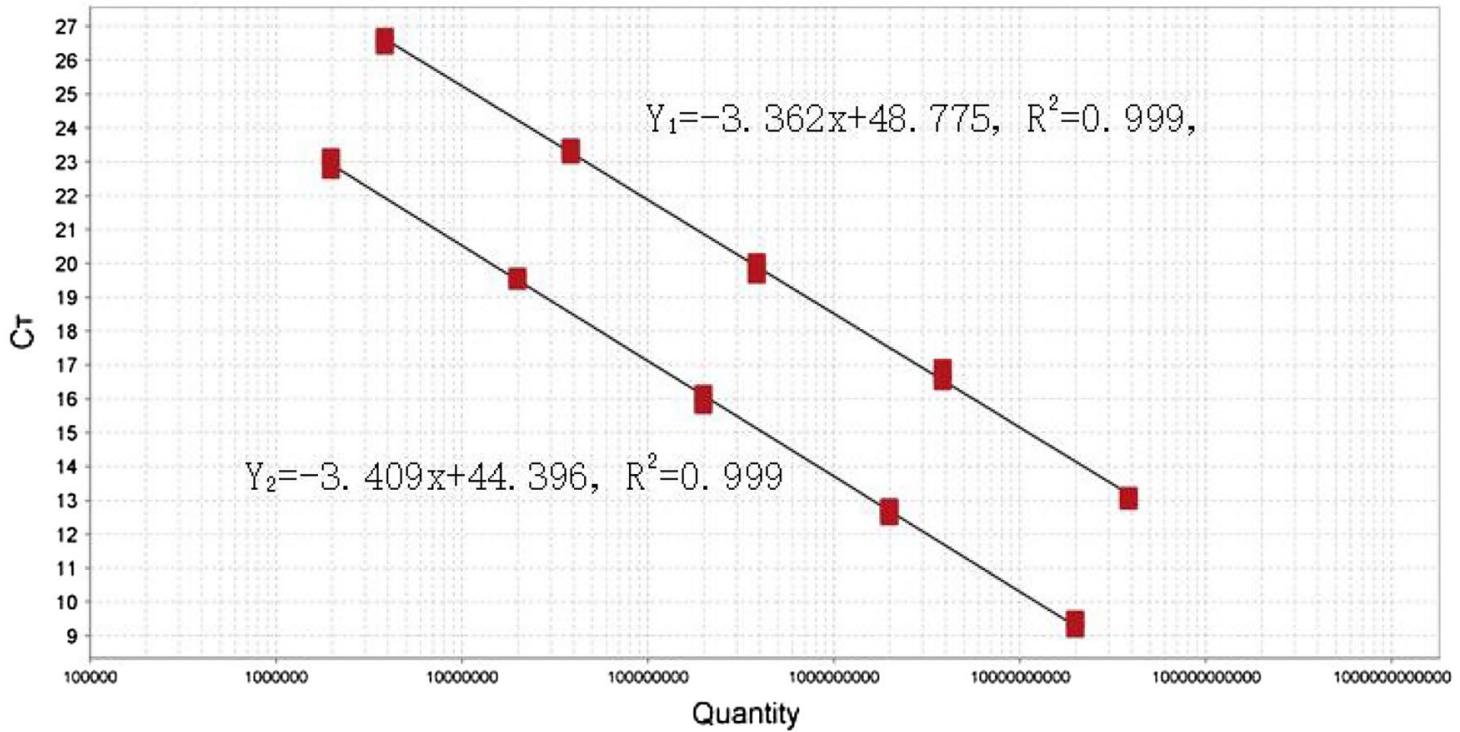

Fig. 2 Amplification plot for the duplex RT-qPCR assay using serially diluted plasmids (a). Amplification plots 1-5 represent gyrB gene-containing plasmid ranging from $1.97 \times 10^{10}$ to $1.97 \times 10^{6}$ copies/ $\mu$ L, respectively. Amplification plots $6-10$ represent invA gene-containing plasmid ranging from $1.45 \times 10^{10}$ to $1.45 \times 10^{6}$ copies/ $\mu \mathrm{L}$, respectively. Standard curves for the duplex RT-qPCR assay $(\mathbf{b}) . Y_{1}$ and $Y_{2}$ are standard curves using invA gene- and gyrB gene-containing plasmids, respectively

plasmids. Standard curve slopes are -3.362 and -3.409 for the detection of $i n v A$ and $g y r B$, respectively, indicating an amplification efficiency of $98.346 \%$ and $96.49 \%$. A correlation coefficient consistently higher than 0.999 indicates effective simultaneous detection of two kinds of pathogens in one real-time qPCR assay without cross-reaction.

\section{Tests of reproducibility and stability}

Five recombinant $i n v A$ and $g y r B$ plasmid dilutions were simultaneously used as substrates to evaluate the reproducibility and stability of the assay. As shown in Additional file 1: Table S5, the standard deviation was no more than 0.153 for all reactions, and the coefficient of 
variation was less than $0.73 \%$. Additionally, Ct values for the same plasmid samples obtained from same experiments were determined to analyze the performance of the developed real-time qPCR method. The results showed that amplification plots for all 96 replicate reactions were almost coincident in the vicinity of the threshold line (Additional file 2: Fig. S1). Thus, the established quantitative real-time PCR assay has high stability and reproducibility.

\section{Duplex real-time qPCR analysis of imported feed stuffs} Imported feedstuffs not infected with either Salmonella spp. or S. fonticola were artificially contaminated with the corresponding pathogens. Three feed samples were contaminated with Salmonella enteritidis and S. fonticola, while four samples were contaminated with Salmonella enteritidis only. Expected fluorescent signals were observed among all artificially contaminated feed samples by the end of amplification (Fig. 3). Meanwhile, the results of the detection of artificial contaminated samples were consistent with the national standard method (GB/ T13091-2018) that was also employed for verification.

\section{Discussion}

Many target genes for the detection of Salmonella genus have been reported, including afgA, hilA, spvC, sef (Crăciunaş et al. 2012; Mann et al. 2013), fliC, fliB, iroB, $r f b J$ (Shanmugasundaram et al. 2009), ompC (Ngan et al. 2010), spvR (Mahon et al. 1993), fimA (Cano et al. 1993), viaB (Hashimoto et al. 1995),etc. However, they have shortcomings for the identification of Salmonella species, and false-positives limit the diagnostic process. At present, quorum sensing-related such as $\operatorname{lux} S$ and $\operatorname{gyr} B$ are widely used, along with virulence genes $i n v H$, sopE, hilA, and $i n v A$ in the SP11, sugR, rhuM, and iacP in the SPI-3 pathogenicity island, and $s p v B$ and $s p v C$ in virulence plasmids. Of these, invA, which encodes an epithelial cell surface protein, is present in all Salmonella species, and is the most widely reported target gene in the Salmonella genus. Primers and probes for the diagnosis of Salmonella spp. based on this conserved gene are highly specific, hence invA was selected as the target gene for real-time qPCR detection of Salmonella species in the present study.

The 16S rDNA gene has been used for classification and identification of Serratia species in previous studies, as has the quorum sensing gene $\operatorname{lu} x S$ (Zhu et al. 2008), which was employed in real-time qPCR (Joyner et al. 2014). In addition, several studies used carbapenem antibiotic resistance genes for identification of Serratia species (Yamamoto and Harayama 1996). The $g y r B$ gene, encoding the B subunit of DNA gyrase (GyrB) that forms topoisomerase II, an essential protein in replication, transcription, DNA synthesis, and

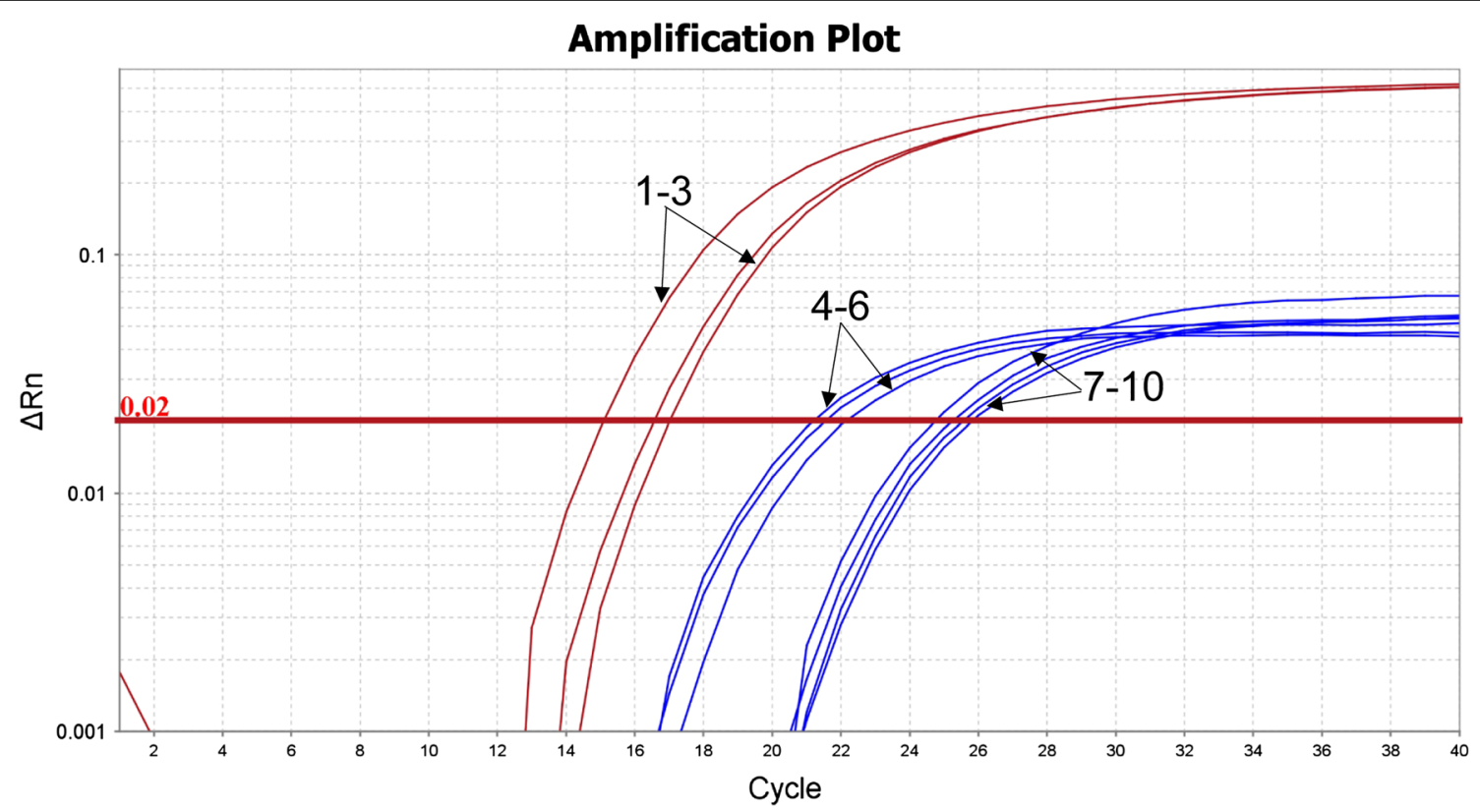

Fig. 3 Detected amplification plot of artificially contaminated Feedstuffs. Red curves 1-3 and blue curves 4-6 represent the amplification plots of gyrB and invA-specific primers, respectively, which correspond to three samples artificially contaminated with Salmonella enteritidis and S. fonticola. Blue curves 7-10 represent the amplification plots of invA-specific primers, which correspond to four samples artificially contaminated with Salmonella enteritidis only 
maintenance of the DNA supercoiled structure, is more reliable than the 16S rDNA gene for the identification of bacterial species (Gellert et al. 1976). The proteincoding gyrB gene contains more genetic information than the non-protein-coding $16 \mathrm{~S} \mathrm{rDNA}$, resulting in a greater capacity to distinguish bacterial species (Kasai et al. 1998). Thus, the gyrB gene was selected for discriminating S. fonticola and Salmonella spp. using realtime qPCR.

Real-time qPCR requires stricter primers, amplification products, and reaction conditions than conventional PCR. Primers used for real-time $\mathrm{qPCR}$ are typically $18-30$ bp in length. Shorter primers $(<15$ nucleotides) can be combined efficiently, but often to the detriment of specificity. By contrast, longer primers often display enhanced specificity but may also hybridize with the wrong pairing sequence, reducing specificity and decreasing the efficiency of hybridization, resulting in diminished PCR amplification. Ideal results are generally obtained when amplifying products of less than $300 \mathrm{bp}$. Therefore, the PCR products selected for differentiating Salmonella spp. and S. fonticola were $199 \mathrm{bp}$ and $94 \mathrm{bp}$, respectively. Different annealing temperatures were tested to determine the optimum annealing temperature of the two pairs of primers, in order to reduce the influence of annealing temperature on the duplex real-time qPCR experiment. An annealing temperature of $64{ }^{\circ} \mathrm{C}$ was found to be optimal.

The duplex real-time qPCR approach established for the rapid detection of Salmonella spp. and S. fonticola in imported feedstuffs was characterized by a high correlation coefficient between the $\mathrm{Ct}$ value and the logarithm of the initial copy number $\left(R^{2}=0.999\right)$. Additionally, parameters including slope, $y$-axis intercept, and amplification efficiency between duplex realtime PCR and single real-time PCR were compared. As shown in Additional file 1: Table S6, the slope of the standard curve and its intercept on the y-axis are approximately equal, and the amplification efficiency is $\sim 100 \%$. Thus, simultaneous detection of the two pathogens was achieved in a single duplex real-time qPCR amplification assay, and the detection limit of this method is suitable for daily inspection and quarantine work. In summary, the rapid diagnostic method established in this study has many advantages, including a low detection limit and high repeatability. It is also rapid and convenient to deploy, since the results can be obtained within several hours after pre-enriching, representing a significant improvement in efficiency for detecting Salmonella spp. in imported animal-derived feedstuffs during quarantine work. This method is of great theoretical and practical value for ensuring the safety of imported feedstuffs.

\section{Supplementary information}

Supplementary information accompanies this paper at https://doi. org/10.1186/s13568-020-01144-x.

Additional file 1: Table S1. Salmonella spp. strains used in this study. Table S2. Serratia genus strains used in this study. Table S3. Other strains used in this study. Table S4. Real-time GPCR primer pairs and probes used in this study. Table S5. Reproducibility and stability test of the duplex realtime PCR. Table S6. Parameters comparison between duplex real-time $P C R$ and single real-time PCR.

Additional file 2: Fig. S1. Repeatability and stability test of RT-qPCR. 96 amplification plots for detection of Salmonella enteritidis (A) and S. fonticola (B).

\section{Acknowledgements}

We are grateful for support from the 13th Five-Year State Key Development Program, the National Natural Science Foundation of China, Science Program of General Administration of Quality Supervision, Inspection and Quarantine of P.R.C and Science Program of Fujian Entry-Exit Inspection and Quarantine Bureau of P.R.C.

\section{Authors' contributions}

YH, WW, DY designed, supervised, and coordinated the study. JR, TZ, TZ, JZ and SY, performed the study, analyzed and interpreted the data. WW and JR were involved in analyzing and processing the sequencing data. JR wrote the manuscript with the help of WW. All authors read and approved the final manuscript.

\section{Funding}

This work was supported by the 13th Five-Year State Key Development Program (Grant Number 2016YFD0501310), the National Natural Science Foundation of China (Grant Number 31272606), Science Program of General Administration of Quality Supervision, Inspection and Quarantine of P.R.C (Program Number 2016IK030) and Science Program of Fujian Entry-Exit Inspection and Quarantine Bureau of P.R.C (Program Number FJ2015-JS002).

\section{Availability of data and materials}

All data generated and analyzed during this study are included in this published article.

Ethics approval and consent to participate Not applicable.

\section{Consent for publication}

Not applicable.

\section{Competing interests}

The authors declare that they have no competing interests.

\section{Author details}

${ }^{1}$ College of Life Sciences, Fujian Agriculture and Forestry University, Fuzhou 350002, Fujian, People's Republic of China. ${ }^{2}$ Fujian Key Laboratory of Traditional Chinese Veterinary Medicine and Animal Health, Fujian Agriculture and Forestry University, Fuzhou 350002, Fujian, People's Republic of China. ${ }^{3}$ Fujian Key Laboratory for Technology Research of Inspection and Quarantine, Technology Center of Fuzhou Customs District, Fuzhou 350002, Fujian, People's Republic of China. ${ }^{4}$ College of Animal Science, Zhejiang University, Hangzhou 310058, Zhejiang, People's Republic of China.

Received: 20 September 2020 Accepted: 5 November 2020 Published online: 24 November 2020

\section{References \\ Aiyar A (2000) The use of CLUSTAL W and CLUSTAL X for multiple sequence alignment. Meth Mol Biol 132(132):221}


Altschul SF, Madden TL, Schäffer AA, Zhang J, Zhang Z, Miller W, Lipman DJ (1997) Gapped BLAST and PSI-BLAST: a new generation of protein database search programs. Nucleic Acids Res 25(17):3389

Bollet C, Gainnier M, Sainty JM, Orhesser P, Micco PD (1991) Serratia fonticola isolated from a leg abscess. J Clin Microbiol 29(4):834-835

Cano RJ, Rasmussen SR, Sánchez FG, Palomares JC (1993) Fluorescent detection-polymerase chain reaction (FD-PCR) assay on microwell plates as a screening test for salmonellas in foods. J Appl Bacteriol 75(3):247-253

Chen Y, Wu D, Sun M, Deng M, Cui S, Liang C, Geng J, Sun T, Long L, Xiao X (2016) Serum bactericidal assay: new role in Salmonella detection. J Aoac Int 99(1):124

Cornegliani L, Corona A, Vercelli A, Roccabianca P (2015) Identification by realtime PCR with SYBR Green of Leishmania spp. and Serratia marcescens in canine 'sterile' cutaneous nodular lesions. Vet Dermatol 26(3):186-e38

Crăciunaş C, Keul AL, Flonta M, Cristea M (2012) DNA-based diagnostic tests for Salmonella strains targeting hilA, agfA, spvC and sef genes. J Environ Manage 95(2):S15

Gavini F, Ferragut C, Izard D, Trinel PA, Leclerc H, Lefebvre B, Mossel DAA (1979) Serratia fonticola, a new species from water. I J Syst Bacteriol 29(2):92-101

Gellert M, Mizuuchi K, O'Dea MH, Nash HA (1976) DNA gyrase: an enzyme that introduces superhelical turns into DNA. Proc Natl Acad Sci U S A 73(11):3872

Hashimoto Y, Itho Y, Fujinaga Y, Khan AQ, Sultana F, Miyake M, Hirose K, Yamamoto H, Ezaki T (1995) Development of nested PCR based on the ViaB sequence to detect Salmonella typhi. J Clin Microbiol 33(11):302-318

Hurst MRH, Young SD, O'Callaghan M (2008) Development of a speciesspecific probe for detection of Serratia entomophila in soil. N Z Plant Prot 61:222-228

Iwaya A, Nakagawa S, Iwakura N, Taneike I, Kurihara M, Kuwano T, Gondaira F, Endo M, Hatakeyama K, Yamamoto T (2005) Rapid and quantitative detection of blood Serratia marcescens by a real-time PCR assay: its clinical application and evaluation in a mouse infection model. Fems Microbiol Lett 248(2):163

Jain S, Chattopadhyay S, Jackeray R, Abid Z, Singh H (2016) Detection of Salmonella typhi utilizing bioconjugated fluorescent polymeric nanoparticles. J Nano Res 18(5):1-11

Joyner J, Wanless D, Sinigalliano CD, Lipp EK (2014) Use of quantitative realtime PCR for direct detection of Serratia marcescens in marine and other aquatic environments. App Environ Microbiol 80(5):1679

Kasai H, Watanabe K, Gasteiger E, Bairoch A, Isono K, Yamamoto S, Harayama S (1998) Construction of the gyrB database for the identification and classification of bacteria. Genome Inform Workshop Genome Inform 9(4):13

Kunimoto D, Rennie R, Citron DM, Goldstein EJ (2004) Bacteriology of a bear bite wound to a human: case report. J Clin Microbiol 42(7):3374

Mahon J, Lax AJ (1993) A quantitative polymerase chain reaction method for the detection in avian faeces of Salmonellas carrying the spvR gene. Epidemiol \& Infect 111(3):455

Mann E, Hein I, Mester P, Stessl B, Rossmanith P, Wagner M, Dzieciol M (2013) A robust and poisson validated quantitative $5^{\prime}$ nuclease TaqMan ${ }^{\circledR}$ real-time PCR assay targeting fimA for the rapid detection of Salmonella spp. Food Food Anal Meth 6(4):991-995
Nam HM, Srinivasan V, Gillespie BE, Murinda SE, Oliver SP (2005) Application of SYBR green real-time PCR assay for specific detection of Salmonella spp. in dairy farm environmental samples. J Food Microbiol 102(2):161-71

Ngan GJ, Ng LM, Lin RT, Teo JW (2010) Development of a novel multiplex PCR for the detection and differentiation of Salmonella enterica serovars Typhi and Paratyphi A. Res Microbiol 161(4):243-248

Perelle S, Dilasser F, Malorny B, Grout J, Hoorfar J, Fach P (2004) Comparison of PCR-ELISA and LightCycler real-time PCR assays for detecting Salmonella spp. in milk and meat samples. Mol Cell Probes 18(6):409

Rd FJ, Davis BR, Hickmanbrenner FW, Mcwhorter A, Huntleycarter GP, Asbury MA, Riddle C, Wathengrady HG, Elias C, Fanning GR (1985) Biochemical identification of new species and biogroups of Enterobacteriaceae isolated from clinical specimens. J Clin Microbiol 21(1):46

Ruan JH, Wang WJ, Zhang TY, Bai QY, Zheng T, Zhang ZD, Wu LY, Huang YF, Yu DJ (2017) Rapid detection of Serratia fonticola by TaqMan quantitative real-time PCR using primers targeting the gyrB Gene. Curr Microbiol 74(132):1-6

Shanmugasundaram M, Radhika M, Murali HS, Batra HV (2009) Detection of Salmonella enterica serovar Typhimurium by selective amplification of fliC, fljB, iroB, invA, rfbJ, STM2755, STM4497 genes by polymerase chain reaction in a monoplex and multiplex format. World J Microbiol Biot 25(8):1385-1394

Tasic S, Obradovic D, Tasic I (2013) Characterization of Serratia fonticola, an opportunistic pathogen isolated from drinking water. Arch Biol Sci 65(3):899-904

Tomás D, Rodrigo A, Hernández M, Ferrús MA (2009) Validation of real-time PCR and enzyme-linked fluorescent assay-based methods for detection of Salmonella spp. Chicken Feces Samples Food Anal Meth 2(3):180-189

Whelan JA, Russell NB, Whelan MA (2003) A method for the absolute quantification of CDNA using real-time PCR. J Immunol Methods 278(1-2):261-269

Yamamoto S, Harayama S (1996) Phylogenetic analysis of Acinetobacter strains based on the nucleotide sequences of gyrB genes and on the amino acid sequences of their products. Int J Syst Bacteriol 46(2):506

Zhu H, Sun SJ, Dang HY (2008) PCR detection of Serratia spp using primers targeting pfs and luxS genes involved in Al-2-dependent quorum sensing. Curr Microbiol 57(4):326-330

\section{Publisher's Note}

Springer Nature remains neutral with regard to jurisdictional claims in published maps and institutional affiliations.

\section{Submit your manuscript to a SpringerOpen ${ }^{\circ}$ journal and benefit from:}

- Convenient online submission

- Rigorous peer review

- Open access: articles freely available online

- High visibility within the field

- Retaining the copyright to your article

Submit your next manuscript at springeropen.com 